CASE REPORTS

\title{
INTRACARDIAC ENDODERMAL HETEROTOPIA
}

\author{
BY
}

\author{
M. HONEY and M. A. AXELRAD
}

From the Departments of Cardiology, St. Bartholomew's Hospital, and of Pathology, Chase Farm Hospital

The patient reported here had an intracardiac tumour which in many respects resembled an atrial myxoma. Histological examination showed this to be primarily an epithelial tumour, which is attributed to endodermal heterotopia. The results of investigations in this condition have not hitherto been described.

\section{Case History}

A housewife, aged 45, gave a history of increasing fatigue and shortness of breath on exertion for three years. Paroxysmal atrial fibrillation had been noted, and three months before her admission there was transient weakness of the right hand, attributed to cerebral embolism. Seven years previously a benign epidermoid implantation cyst had been removed from her right arm and a loose fibromatous tumour, which had undergone mucoid degeneration, from her scalp. Careful inquiry revealed no family history of heart disease.

On examination, there was clinical evidence of right ventricular hypertrophy and a dominant " $a$ " wave in the jugular venous pulse. There was a soft pulmonary ejection systolic murmur, a pulmonary ejection click, and a right ventricular third sound. The blood pressure was $210 / 115 \mathrm{~mm}$. Hg. There was a small nodule in the thyroid isthmus.

A cardiogram showed sinus rhythm with evidence of right ventricular hypertrophy; there was a qR in V1 and $\mathrm{qrS}$ in V2. A chest radiograph showed slight cardiac enlargement and prominence of the main pulmonary trunk; a calcified opacity $(1.5 \times 2 \mathrm{~cm}$.) was visible in the lateral and overpenetrated films, situated anteriorly near the apex of the heart. The serum proteins were $8 \cdot 2 \mathrm{~g} . / 100 \mathrm{ml}$. (albumin $5 \cdot 1$, globulin $3 \cdot 1$ ), and electrophoresis showed an increase in $\beta$ and $\gamma$ globulin. The E.S.R. (Westergren) was $47 \mathrm{~mm}$. in one hour. The urine contained no 5-hydroxyindoleacetic acid.

Right Heart Catheterization. There was a small systolic gradient across the pulmonary valve and a further small gradient in the outflow tract (Fig. 1); there was a small tricuspid diastolic gradient with an $11 \mathrm{~mm}$. presystolic gradient, corresponding to a giant "a" wave (Fig. 2). Slight arterial unsaturation (87.5\%) was attributed to shunting through a patent foramen ovale as a result of the raised right atrial pressure. The cardiac index was $2.81 . / \mathrm{min} . / \mathrm{m} .^{2}$ Difficulty was experienced in negotiating the right ventricular outflow tract and the catheter was noted to take an unusually lateral course. A selective angiocardiogram (Fig. 3A) showed a narrow stream of dye in the lateral part of the right ventricular outflow tract, there being a total failure of the medial part to fill. The right atrium also filled poorly, with a central relatively translucent but ill-defined area $7 \times 5 \mathrm{~cm}$. surrounded by a more densely opacified rim: the atrial filling defect was overlooked at the time. A few hours after cardiac catheterization she had a brief syncopal attack.

The diagnosis of obstructive cardiomyopathy or right ventricular tumour was suggested; surgical exploration was not advised. Her condition deteriorated over the next few months, with increasing fatigue and an episode of tightness in the chest associated with faintness. Seven months later, she was found deeply unconscious, and was admitted to hospital. There were signs of a spastic quadriplegia; the pulmonary systolic murmur was louder, a diastolic murmur was now audible in the tricuspid area, and there was cdema of the ankles. She remained in coma and died two days later. 


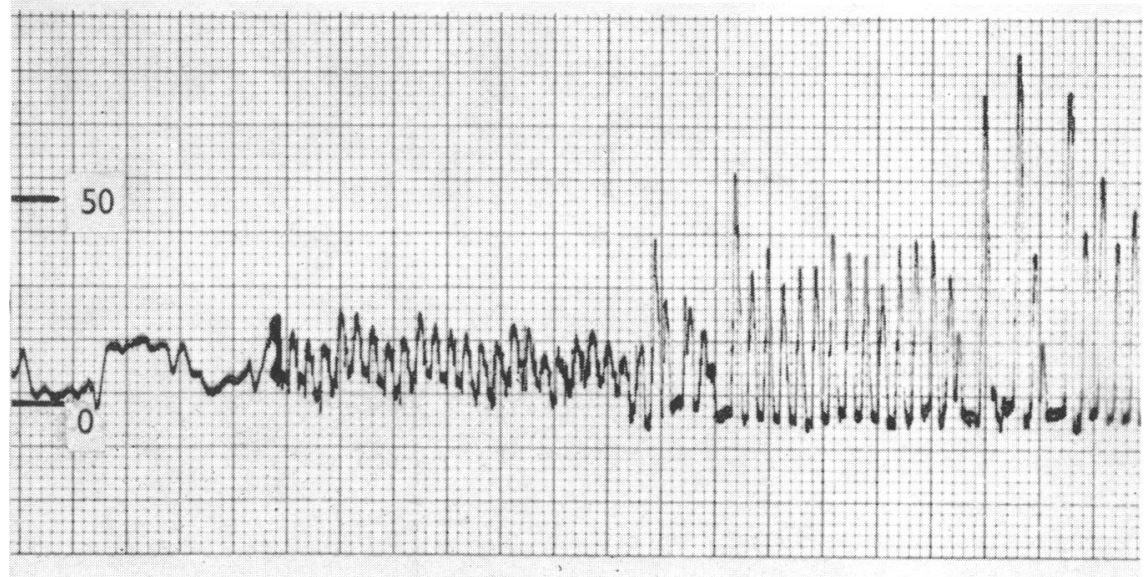

Fig. 1.-Withdrawal record from pulmonary artery to low right ventricle. There is a small gradient at valve level (P.A. 17/5; R.V. immediately below valve $35 /-2$ ); on further withdrawal a run of ectopic beats is followed by a zone with a higher systolic pressure $(48 /-2)$.

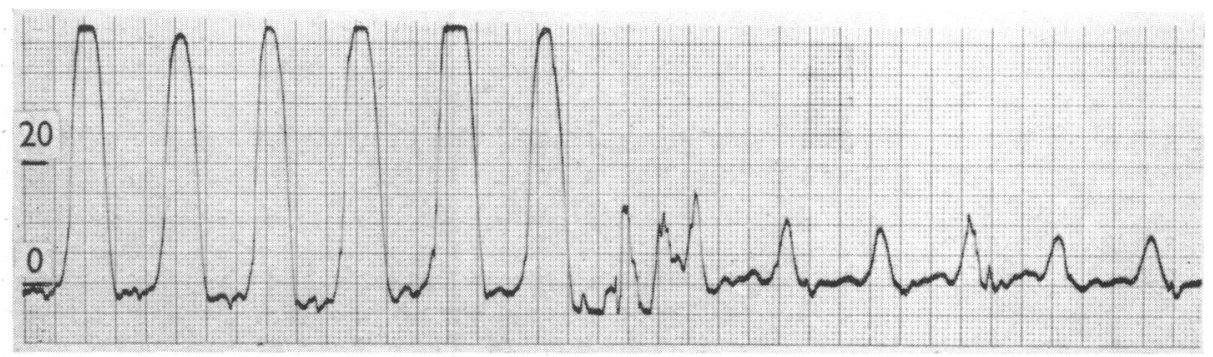

FIG. 2.-Withdrawal across tricuspid valve. There is a $4 \mathrm{~mm}$. tricuspid diastolic mean gradient, with a presystolic gradient of $11 \mathrm{~mm}$., corresponding to a giant "a" wave in the right atrial pressure record. R.V. pressure 48/-2; R.A. mean pressure 3, "a" 11 .

Necropsy. The heart showed slight left and right ventricular hypertrophy and the infundibulum of the right ventricle was dilated: the gross weight was $600 \mathrm{~g}$.

The right atrium was almost entirely filled with a pedunculated mass; the tumour rested in the tricuspid valve orifice but did not extend through it. The pedicle arose from the upper margin of the foramen ovale: the tumour extended through the atrial septum in the region of the foramen ovale and was continuous with a macroscopically similar but smaller mass in the left atrium. The tumour in both atria was lobulated and had a smooth glistening hæmorrhagic surface.

In the infundibulum of the right ventricle there was an elongated mass $11 \mathrm{~cm}$. long and $2.5 \mathrm{~cm}$. in diameter; this was firmly attached by a short wide pedicle to the wall of the ventricle between the anterior cusp of the tricuspid valve and the crista supraventricularis, and there were a few flimsy adhesions between the mass and the wall of the infundibulum and the inferior aspect of the pulmonary valve. Embedded in the centre of the infundibular mass was an irregular calcified nodule $(1.4 \mathrm{~cm}$. diam.), attached to the wall of the ventricle by a short fibrous pedicle. There was a very small pedunculated tumour adherent to the endocardium of the left ventricle. The coronary arteries, valves, and great vessels showed no abnormality. 
There was acute suppurative tracheobronchitis, pulmonary œdema, and slight pulmonary congestion. The kidneys showed multiple small renal infarcts and the ovaries each contained one small follicular cyst. There was a small colloid cyst $(0.5 \mathrm{~cm}$. diameter) in the thyroid gland. In the brain, there were multiple cortical infarcts, mainly in the left cerebral hemisphere, up to $3 \mathrm{~cm}$. in diameter: some of these were recent and some older.

Death was due to acute suppurative tracheobronchitis, following cerebral embolism, resulting from primary cardiac tumour, with heart failure.

Histology of the Atrial Tumour. In the base of the right atrial mass was a well-defined area $12 \mathrm{~mm}$. in diameter showing mucin-containing gland-like spaces lined by mucin-secreting epithelial cells (Fig. 3B). These cells varied in form from flattened and endothelial-like to columnar with basal nuclei and cytoplasmic secretory vacuoles. The left atrial mass and the remainder of the right atrial mass showed a myxomatous appearance with swollen cells in and around thickened vessels. There was no evidence of invasion of the myocardium, and the cellular appearances were unlike those of a malignant tumour. The infundibular mass was old, largely unorganized thrombus. The calcified nodule in the right ventricle was devoid of structure. Sections of the kidney showed emboli, consisting of myxoma-like tissue, in branches of the renal artery.

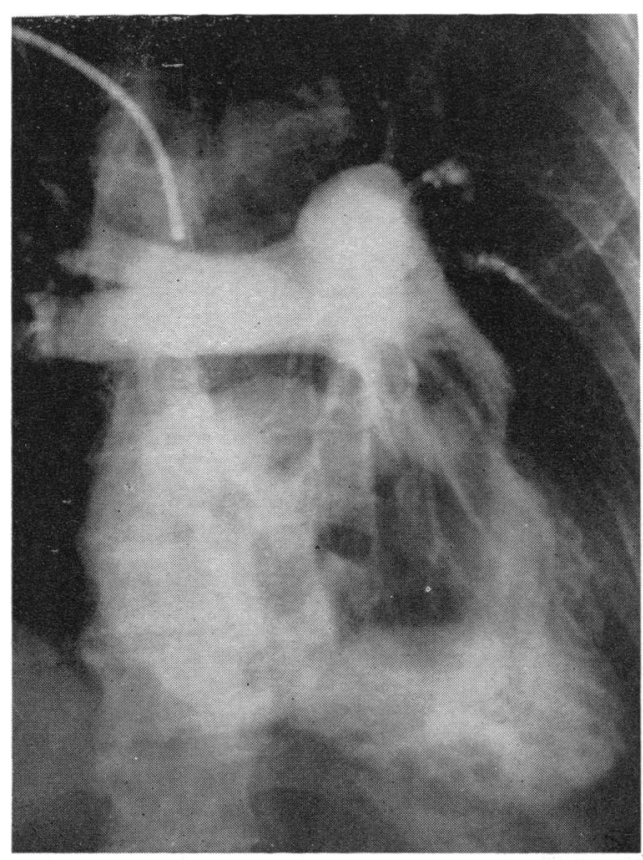

A

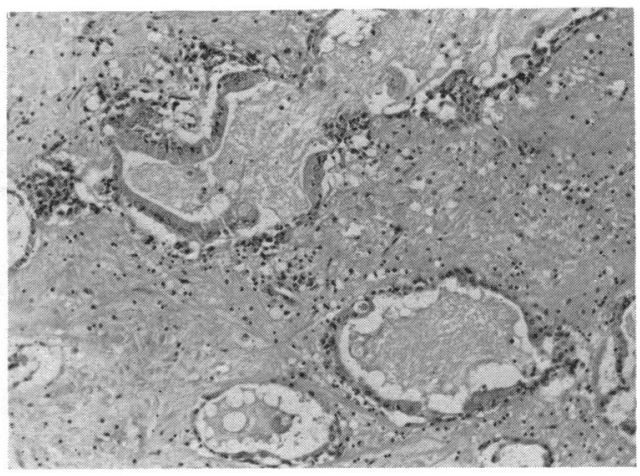

B

FIG. 3 (A).--Selective angiocardiogram, 4-sec. film; $45 \mathrm{ml} .85$ per cent hypaque into superior vena cava. Opaque medium is seen in a narrow stream laterally in the right ventricular outflow tract; there is a large unopacified filling defect medially. In the original, a relative translucency surrounded by a more densely opacified rim can be distinguished in the right atrium. (B).- Photomicrograph of the right atrial tumour. Area of tumour showing gland-like spaces, lined by epithelium and containing mucoid material $(\times 58)$.

\section{DisCUSSION}

Many of the features of this case suggested a diagnosis of atrial myxoma. Cardiac catheterization revealed right ventricular inflow and outflow obstruction, and the angiocardiogram showed filling defects in the right atrium and ventricle. The occurrence of syncope and arterial embolism and the finding of a raised E.S.R. and serum protein abnormalities are also typical. The gross appearance of the tumour, including its origin from the rim of the fossa ovalis, also resembled that of a myxoma. Biatrial myxomas occur (Nichols and Hennigar, 1959; Cumming and Finkel, 1961) and 
implantation of myxoma tissue on the endocardium has been recorded (Adams et al., 1961). It is likely that the calcified nodule in the right ventricle, upon which the mass of thrombus in the infundibulum appears to have formed, developed from such an implantation.

However, the presence of epithelial elements in this tumour clearly differentiates it from myxoma; the overlying myxoma-like tissue may have been œdematous organized thrombus. Willis (1958) collected 12 cases from the published reports, in which there were tumour-like or cystic lesions in the heart, thought by him to be epithelial; the epithelial elements were columnar, cuboidal, ciliated, or stratified squamous, and in many of the cases had a glandular structure and secreted mucus. Ten of the patients were adults. In 7 cases, the lesion arose in the atrial septum; in 5 of these the bundle of His was interrupted in the lower part of the atrial septum with the production of heart block. Of the 12 cases the one most closely resembling ours was that of Anderson and Dmytryk (1946), who described a right atrial tumour that contained regions of gland-like spaces lined by mucin-secreting cells (a picture remarkably like that in Fig. 3B) and elsewhere had a myxomatous appearance.

The structure from which these heterotopias are derived is disputed. Anderson and Dmytryk (1946) suggested that the tumour in their case arose from a pericardial element, and was a mesothelial rather than an epithelial heterotopia. Willis (1958) drew attention to the proximity of the primitive heart tube to the ventral aspect of the foregut, and suggested that these heterotopias are the result of translocation of fragments of foregut endoderm, normally destined to become pharyngeal, œsophageal, or thyroglossal epithelium, into the dorsal mesocardium and into the developing heart; he therefore described this condition as intracardiac endodermal heterotopia. The presence of columnar ciliated and cornifying stratified squamous cells is difficult to explain on a mesothelial or endothelial basis, and strongly suggests that foregut endoderm is the tissue of origin. Thus the available evidence favours the endodermal hypothesis in many of the reported cases, and in the remainder this interpretation still appears as likely as any other suggested.

\section{Summary}

The patient reported here had a tumour in the right and left atria which arose from the atrial septum and in many ways resembled a myxoma. The microscopic appearance of the tumour was that of epithelial heterotopia, with gland-like spaces lined by mucus-secreting epithelium. Brief reference is made to similar previously reported patients and to the pathogenesis of the condition.

We wish to thank Dr. G. W. Hayward, Dr. C. Allan Birch, and Dr. J. T. Prendiville for permission to publish this case. We are particularly indebted to Professor R. A. Willis for his views on the sections, and to Dr. A. G. Stansfeld and Dr. R. Finlayson for their observations on the pathological features of this case.

\section{References}

Adams, C. W., Collins, H. A., Dummit, E. S., and Allen, J. H. (1961). Amer. J. Cardiol., 7, 176. Anderson, W. A. D., and Dmytryk, E. T. (1946). Amer. J. Path., 22, 337.

Cumming, G. R., and Finkel, K. (1961). J. Pediat., 58, 559.

Nichols, J., and Hennigar, G. (1959). Arch. Path., 67, 24.

Willis, R. A. (1958). The Borderland of Embryology and Pathology. Butterworth, London. 